ISSN: $1130-3743$

\title{
EL PROBLEMA DEL ESTRUCTURALISMO Y LA EDUCACIÓN MULTICULTURAL
}

\section{THE PROBLEM OF STRUCTURALISM AND MULTICULTURAL EDUCATION}

DAVID REYERO GARCÍA

Universidad Complutense. Departamento de Teoría e Historia de la Educación. Facultad de Educación. Edificio La Almudena, $P^{\circ}$ de Juan XXIII s/n., 28040 Madrid.

RESUMEN

El artículo pretende acercarse a la educación multicultural desde el punto de vista teórico, planteando la necesidad de encontrar apoyo en una teoría antropológica. Esta teoría antropológica no parece que pueda ser el estructuralismo, que considera los fenómenos culturales como epifenómenos de la estructura lógica del cerebro. La solución puede estar en una antropología hermenéutica que nos ayude a ponernos en contacto con el otro cultural.

\section{SUMMARY}

The purpose of the article isto approach to the multicultural education from a theoretical point of view, poseing the necessity of finding support in an anthropogical theory. The structuralism does not seem to be this theory because it considerers the cuturals events as epiphenomena of the logical structure of the mind. The solution could be an hermeneutic anthropology that help us to contact with the "alter" cultural. 
“La constitución de 1795, de igual manera que las anteriores, está hecha para el hombre. Ahora bien, no hay hombres en el mundo. Durante mi vida, he visto franceses, italianos, rusos, etc.; sé incluso, gracias a Montesquieu, que se puede ser persa: pero, en cuanto al hombre, declaro no haberlo encontrado en mi vida; si existe, es en mi total ignorancia [...]

¿Qué es una constitución? ¿No es la solución del problema siguiente?

Dadas la población, las costumbres, la religión, la situación geográfica, las relaciones políticas, la riqueza, las buenas y las malas cualidades de una cierta Nación, encontrar las leyes que le convengan.

Ahora bien, este problema no está ni abordado en la constitución de 1795, que no ha pensado más que en el hombre."

Joseph de Maistre (1796) Consideraciones sobre Francia.

\section{INTRODUCCIÓN}

La educación multicultural es un término de gran actualidad en el mundo de la educación, pero esa actualidad, puede ser sólo fruto de una moda o tener una consistencia mayor.

Existen muchos datos que confirman la necesidad de promover una educación multicultural, estos datos se encuentran ligados a la situación que nos ofrece el mundo actual, la cual se caracteriza por una disminución de las distancias gracias a la mejora de las comunicaciones y una mayor movilidad de las gentes, estos fenómenos pueden resumirse en la tradicional expresión de "aldea global". Esta circunstancia ha favorecido una mayor relación entre modos de vida y culturas muy diferentes, que muchas veces ha provocado rechazos, incomprensiones, etc., y que desgraciadamente rara vez se ha aprovechado para el enriquecimiento de los pueblos.

Si una vez situados estos parámetros, aceptamos la necesidad de que la educación actual deba ser multicultural de alguna manera, necesitamos encontrar un modelo antropológico que la haga posible.

Intentaré demostrar en este artículo que como modelo antropológico posibilitador de la educación multicultural, el paradigma estructuralista, representado en la obra de C. Lévi-Strauss, resulta insuficiente a la hora de buscar un apoyo teórico a las planificaciones de educación multicutural, o dicho de otro modo, el estructuralismo no ayuda ni al como ni al por qué de la educación multicultural.

Para demostrar mi tesis, comenzaré por describir el pensamiento de LéviStrauss, luego realizaré una crítica sobre él basándome sobre todo en C. Geertz, y por último extrapolaré las conclusiones de dicha crítica antropológica al mundo de la educación.

\section{El estruCtURALISMO DE LÉVI-STRAUSS}

En rigor todo pensamiento filosófico o científico es de por si estructuralista, sin embargo, hoy en día reservamos este nombre para referirnos al pensamiento desarrollado por el filósofo y antropólogo francés Claude Lévi-Strauss. 
Tradicionalmente la metafísica occidental siempre ha buscado estructuras fundamentales y fundantes tanto de un origen como de una finalidad, es decir creadoras de un centro en torno al cual pivote todo lo demás, un lugar meta-físico, pero que desde su trascendentalidad pueda explicar el cambio aparente. Lo novedoso del estructuralismo de Lévi-Strauss, no es por lo tanto la noción de estructura, propia del pensamiento de occidente sino su descentramiento, su ruptura con el determinismo fruto de las estructuras rígidas, con el historicismo consecuencia de un "telos" universal hacia el que dirigirse, y con la noción cartesiana de sujeto fundante y creador de la realidad. Sin embargo, la revolución iniciada por LéviStrauss del concepto de estructura, no es total, ya que a pesar de ese descentramiento, en el desarrollo de su pensamiento, su teoría curiosamente sólo sirve para explicar las semejanzas culturales, no las diferencias entre las mismas (Harris, 1994: 625).

La concepción estructuralista de Lévi-Strauss tiene cuatro apoyos esenciales, lo que él denominó sus «tres amantes" Freud, Marx y la geología, y la influencia de la ciencia lingüística fonológica.

La subjetividad nacida en la modernidad con Descartes, Leibniz y Kant, es trascendente (en el sentido kantiano) ya que funda y jerarquiza el conocimiento de todo lo real, su teoría epistemológica determina la ontología y tiene sobre ella primacía. Sin embargo esta concepción del cógito, que da razón del ser real, comenzó a ser puesta en entredicho principalmente con Marx y Freud. Para Marx el pensamiento no puede ser una entidad creadora de lo real ya que ella misma es fruto de una infraestructura de relaciones sociales y en último término económicas. Freud por su parte, pone el acento en las fuerzas inconscientes e incontrolables del ser humano, que adquieren una importancia central y que demuestran que por encima de lo racional existen unas estructuras más significativas y con mayor valor a la hora de explicar la conducta humana. El estructuralismo de LéviStrauss, recoge las críticas de Freud y Marx al sujeto cartesiano y en cierto modo kantiano y elabora una teoría del hombre novedosa en la que mantiene por una parte la trascendentalidad (universalidad) de las estructuras pero no del sujeto individual el cual es más bien un precipitado, un resultado de las relaciones estructurales.

De la ciencia geológica aprenderá que detrás de los fenómenos aparentemente desorganizados, existe un orden estructural desde el que se puede leer el sentido y la génesis de los acontecimientos. Lévi-Strauss pretende aplicar este método a la antropología y convertirla en una geología de los hechos sociales.

Por último esta concepción de estructura social se apoya en la lingüística y toma la noción de estructura como equivalente a la de "gramática de lo social", cualitativamente diferente de lo natural y lo biológico. Este salto cualitativo en antropología, rompe con la tradición funcionalista de Radcliffe Brown. Para este como para Malinowski existe una analogía entre la estructura social y la estructura orgánica. Lévi-Strauss por su parte reclama una separación entre ambas, al igual que sucede entre gramática y lengua hablada. (Lévi-Strauss, 1984a: 274-275).

¿Cómo surgen las estructuras sociales en el hombre, dónde está su génesis que marca la diferencia cualitativa entre las estructuras orgánicas y las estructuras 
culturales? La respuesta a esta pregunta la encontramos en el estudio del parentesco que constituye uno de los temas esenciales y más clásicos en la historia de la antropología cultural. Lévi-Strauss, le confiere una significación que va más allá de lo aparente, y reconoce en la diversidad de sistemas de matrimonio preferencial y de matrimonios prohibidos, la estructura más elemental de la sociedad y la que determina el paso de la naturaleza a la cultura. Sus argumentaciones y su interés por el tema, determinan toda una forma de pensar el efecto humanidad, un efecto distingible de la historia,la sociología o la razón, y que reconocemos con el nombre de cultura, objeto de estudio de aquellos que se denominan a sí mismos antropólogos.

Para Lévi-Strauss la clave que explica el nacimiento de la cultura radica en el tabú Universal de la prohibición del incesto, que comparte con la naturaleza su universalidad y con la cultura el carácter de norma. Lévi-Strauss analiza tres explicaciones que él considera equivocadas y que pretenden explicar la prohibición del incesto (Lévi-Strauss, 1991b: 30-49). La primera de ellas es la que basa dicha prohibición en las graves malformaciones que se derivarían de la práctica endogámica, esto no es problema para él ya que las malformaciones sólo tienen lugar debido a que la endogamia ha sido tradicionalmente evitada, si esto no hubiera sido así, la selección natural de la especie hace tiempo que nos hubiera librado de los genes recesivos, al igual que sucede con los criadores de animales que cuando quieren mejorar la especie emparentan ejemplares consanguíneos.

La segunda explicación errónea es la que basa este tabú en la llamada voz de la sangre, en una especie de repugnancia instintiva a emparentar con parientes cercanos, sin embargo Lévi-Strauss recurre al psicoanálisis y a las costumbres de otras culturas como los "azande" y los "hehe", para mostrar lo discutible de esta idea.

La tercera explicación que el antropólogo francés examina es la que se apoya en la creencia en que la convivencia continua que experimentan los hermanos o los familiares que habitan en un mismo hogar, inhibe el interés sexual entre ellos. Lévi-Strauss, como en el caso anterior se apoya en el ejemplo de otras sociedades en las que sucede todo lo contrario.

La prohibición del incesto por lo tanto escapa a explicaciones puramente naturales, y tampoco puede reducirse a una regla más entre las demás reglas dentro del complejo social debido a que, en opinión de Lévi-Strauss, es la única regla de carácter universal. En definitiva la prohibición del incesto constituye el momento en el cual se pasa de la naturaleza a la cultura y bajo el cual nace una estructura radicalmente nueva que se "superpone" a las estructuras más simples, generando un nuevo orden (Lévi-Strauss, 1991a: 59-60).

Lévi-Strauss recurre a la ciencia lingüística a la hora de explicar esta nueva estructura sobre la que se asienta la cultura humana, la utilización de este método enlaza con el programa iniciado ya antes por F. Boas, (Gardner, 1988, 258-159) pero es Lévi-Strauss quien le otorga una dimensión más considerable. Lévi-Strauss se apoya en el método utilizado por la fonología de Turbetzkov, el cual se apoya en cuatro pasos fundamentales. Primero, pasa del estudio de las estructuras lingüísticas conscientes a las inconscientes. Segundo, rehusa tratar los términos como 
independientes y toma como base de su análisis las relaciones entre ellos. Tercero, introduce la noción de sistema. Cuarto, busca descubrir leyes generales, (LéviStrauss, 1984a: 31). Lévi-Strauss aplica esta metodología de conocimiento al estudio de manifestaciones culturales, en concreto él se centra en el estudio de las relaciones de parentesco y en el estudio de los mitos, para lo cual se basa en la idea de que la cultura funciona de la misma manera que el lenguaje:

“Una y otra se edifican por medio de oposiciones y correlaciones, es decir, de relaciones lógicas. De tal manera que el lenguaje puede ser considerado como los cimientos determinados a recibir las estructuras que corresponden a la cultura en sus distintos aspectos, estructuras más complejas a veces, pero del mismo tipo que las del lenguaje" (Lévi-Strauss, 1984:63).

Estas estructuras son comunes a todos los hombres tanto al primitivo como al científico, lo único que varia es la naturaleza de las cosas a las que ésta se aplica. Todo pensamiento humano es por lo tanto esencialmente lógico (Gardner, 198:262-266).

Surge además otra consecuencia de la concepción estructuralista, y es la disolución del humanismo trascendente kantiano, en favor de lo que él llama un kantismo sin sujeto trascendental, lo que nos lleva a una crisis y disolución del hombre, de la libertad y de las finalidades conscientes (Lévi-Strauss, 1984b: 357-359).

La importancia concedida por Lévi-Strauss a las estructuras del lenguaje y de la mente a la hora de entender la cultura, permitieron introducir la cognición en los estudios antropológicos que, posteriormente, han dado lugar a la etnociencia y a la antropología cognitiva (Gardner, 1988:262-269).

El enfoque antropológico estructuralista puede, por lo tanto, ser de gran utilidad a la hora de estudiar al hombre desde el punto de vista cognitivo, pero en la educación multicultural podemos esperar algo más. Podemos partir de la idea de que lo cultural es cualitativamente diferente de lo psicológico y que no se puede reducir a ello. La teoría estructuralista, como ahora veremos, resulta insuficiente por eso necesitamos de una teoría diferente a la hora de intentar comprender los fenómenos propios de la cultura.

\section{LA CRÍTTCA AL ESTRUCTURALISMO}

Geertz critica el enfoque de Lévi-Strauss, no por su aporte revolucionario con respecto a la noción de estructura descentrada a la que aludí al principio, sino por su mecanismo, ya que si bien se trata de un mecanismo complejo, en opinión de Geertz, se olvida de factores históricos, subestima la dimensión emocional del hombre, y salta prematuramente a la conclusión de que los procesos de pensamiento humano son análogos a los de una computadora tradicional.

Geertz pone en tela de juicio la posibilidad misma, anunciada por Lévi-Strauss a lo largo de toda su obra, de someter a análisis sistemático cerrado y conforme a unas reglas, al estilo de lo que sucede en la lingüística, pautas de conducta y cre- 
encias humanas de carácter polimorfo. Geertz duda de la posibilidad de concebir una gramática universal del actuar humano (Gardner, 1988: 267-268). En resumen, cuestiona la finalidad que guía el trabajo de la escuela estructuralista, de encontrar vivo el contrato social de Rousseau en el corazón de la selva (Geertz, 1989: 48). En el fondo a Lévi-Strauss, como a Rousseau y como a todo el pensamiento ilustrado lo que le interesa no son los hombres sino el "Hombre", un hombre que se encuentra en las universales estructuras de la razón, la base inconmovible de la sociedad humana no es social sino psicológica, lo que Lévi-Strauss ha intentado hacer con la cultura es "una máquina infernal. Esa máquina anula la historia reduce el sentimiento a una sombra del intelecto y reemplaza los espíritus particulares de salvajes particulares que viven en sus selvas particulares por la mentalidad salvaje inmanente en todos nosotros". (Geertz, 1992:295).

La propuesta de Geertz consiste en profundizar en el conocimiento local (Geertz, 1994) que nos ayude a ponernos en relación con el otro. Para Geertz, lo importante no es estudiar si la cultura tiene o no tiene un significado gramatical una estructura donde pueda actuar el hombre, sino que debemos estudiar su sentido semiótico, el hombre es un animal inserto en tramas de significado, "pierde entonces sentido la cuestión de saber si la cultura es conducta estructurada o una estructura de la mente o hasta las dos cosas juntas mezcladas". (Geertz, 1992:25). Lo importante es su significado y su valor, desde este punto de vista, critica la antropología cognitiva (etnociencia), hija directa, como antes hemos visto, de la antropología estructuralista, la cual identifica las culturas con las formas mentales. Para Geertz, esta corriente antropológica, solamente ha dado lugar perfectas descripciones culturales de carácter formal en las que es imposible creer. (Geertz, 1992: 20-27).

Esta propuesta de Geertz en orden a conseguir una antropología simbólica hermeútica, que tenga en cuenta lo que los otros cuentan de si mismos, por encima de lo que pueda contar el antropólogo, se apoya en lo que él denomina una "descripción densa", que nos permite conversar con el otro en el sentido más profundo del término, nos permite diferenciar sus guiños cómplices, de sus muecas burlonas. Una antropología de este estilo, no puede ser juzgada en base a la coherencia de las descripciones culturales, sino en base a su poder para "ponernos en contacto". (Geertz, 1992:27-34). No debemos olvidar también el carácter que Geertz confiere a la cultura, como un texto que debemos aprender a leer, y al antropólogo, como un autor literario creador de ficciones (no debemos interpretar el término ficciones como falsedades) que son fruto de su propia lectura de la realidad (Geertz,1989:11-34).

En resumen el debate se centra, utilizando la terminología de M. Harris, en el estudio de la cultura utilizando una metodología "emic", y el estudio de la cultura utilizando una metodología "etic". La metodología emic prueba la validez de sus descripciones, en su corrrespondencia con una visión de los fenómenos culturales que los participantes aceptan como reales, es, en fin, una metodología cuyas creaciones, utilizando terminología hermenéutica, pueden ser leídas de manera significativa por los sujetos estudiados. Mientras que en la metodología etic la validez se mide por la capacidad para generar teorías fructíferas desde el punto de 
vista científico, que nos ayuden a explicar las semejanzas entre diferentes manifestaciones culturales (Harris, 1994:154-156).

\section{LA EDUCACIÓN MULTICULTURAL}

En educación, tradicionalmente, se ha atendido a los estudios culturales etic olvidando que su práctica es principalmente una actividad emic, ya que fundamentalmente se basa en la endoculturación, en la inserción en un determinado medio cultural. La educación trata de hablar con el otro para lo cual es preciso entender sus tramas de significado, la planificación educativa, las adaptaciones curriculares, son aspectos que necesitan ante todo de un conocimiento "emic" del contexto concreto al cual éstas se van a aplicar. Además tal y como esta la situación de la ciencia antropológica y teniendo en cuenta sus, todavía, escasa leyes culturales descubiertas, resulta mucho más útil centrar los esfuerzos en buscar técnicas antropológicas emic.

En el caso de una educación multicultural ${ }^{1}$, la necesidad es aún más evidente debido a la diferencia cultural, cada vez mayor, que existe entre el educador y los educandos. Una planificación que tenga muy en cuenta los aspectos emic de la cultura en la cual se aplica, favorecerá claramente una aprendizaje significativo, además de conseguir una incidencia más real sobre el ambiente. Desde este punto de vista, los programas de educación multicultural que no se toman en serio el contexto de aplicación, se enfrentan con el problema de la generalización y significatividad de los valores que se proponen transmitir.

Una educación así debe permitir, en palabras de Freire, "renombrar» la realidad (Freire; Macedo, 1989), el lenguaje, los conceptos, con los que se juega en las planificaciones educativas, ofrecen una visión de la realidad excesivamente rígida, como lo es, por cierto, el propio lenguaje ${ }^{2}$, de ahí la importancia del renombrar, a partir del lenguaje cultural en el que se actúa. Y de ahí también la crítica que Freire realiza de la educación bancaria como elemento colonizador y anulador de las posibles diferencias culturales.

Además acometer la educación multiculturalidad como fruto de una concepción antropológica al estilo de la que nos propone Clifford Geertz frente a la pro-

1. A la hora de hablar de educación multicultural, no me refiero solamente a la educación que se realiza con sujetos de clara cultura diferencial, sino que tengo en cuenta la existencia de subculturas dentro de una misma sociedad.

2. Sobre la rigidez del lenguaje, resulta muy interesante el cuento de Borges Funes el memorioso. Borges se sirve de este cuento para explicar la existencia de los conceptos y su limitación. Funes se nos presenta como un personaje de memoria tan prodigiosa que recordaba absolutamente todos los matices que percibía a lo lago de su vida, debido a lo cual solamente podía comprender la diversidad, le resultaba imposible comprender, por ejemplo, que un perro de frente a las tres y cuarto pudiera responder a idéntica palabra que el mismo animal de perfil a las ocho y media. El concepto por lo tanto no es otra cosa que el olvido de los matices que la realidad nos ofrece. (Borges J.L. 1989: 121-132). 
puesta de Lévi-Strauss, supone reconocer la inconmensurabilidad última de los discursos del otro cultural. Esto se traduce en el planteamiento de las preguntas de manera abierta y un tanto escéptica que nos impidan valorar ninguna respuesta como definitiva, significa adoptar un cierto adelgazamiento del pensamiento hasta convertirlo en lo que Vattimo denomina pensamiento débil, que significa un pensamiento sin apoyos absolutos y en constante revisión.

Esto no tiene por qué significar un todo vale, sino más bien un nada vale absolutamente y todo esta sujeto a visiones diferentes. La historia y los acontecimientos no son, desde este punto de vista, algo lineal y por tanto irrecuperable, sino que la historia es múltiple y recuperable desde diferentes tradiciones.

El multiculturalismo es por lo tanto una actitud, no sólo de respeto y tolerancia frente a los demás, sino de justicia en una mundo donde no existe una sola verdad ni los acontecimientos fueron una sola vez y de una sola manera. Las diferentes culturas son así necesarias para encontrar los límites de la propia que sin ellas se convertiría en universal e infinita. El educador se debe situar frente a las diferentes culturas de manera no simplemente tolerante y con miedo a penetrar un espacio ajeno, sino que partiendo de su comprensión debe actuar de manera provocativa, situando a cada cultura frente a las otras, no para generar conflicto sino para que cada universo cultural descubra así sus límites y su relatividad. 
DAVID REYERO GARCÍA

EL PROBLEMA DEL ESTRUCTURALISMO Y LA EDUCACIÓN MULTICULTURAL

\section{BiBLIOGRAFÍA}

Borges, J.L. (1989): Ficciones. Alianza Editorial. Madrid.

FREIRE, P; MACEDO, D. (1989): Alfabetización: lectura de la palabra y lectura de la realidad. Paidós MEC. Barcelona.

GARDNER, H. (1988): La nueva ciencia de la mente. Historia de la revolución cognitiva. Paidós. Barcelona.

GEERTZ, C. (1989): El antropólogo como autor. Paidós. Barcelona.

GEERTZ, C. (1992): La interpretación de las culturas. Gedisa. Barcelona.

GEERTZ, C. (1994): Conocimiento local. Paidós. Barcelona.

HARRIS, M. (1994): Introducción a la antropología general. Alianza Universidad. Madrid.

LÉVI-STrAuSs, C. (1984a): Antropología Estructural. EUDEBA. Buenos Aires.

Lévi-STrauss, C. (1984b): El pensamiento salvaje. Fondo de Cultura Económica. México.

Lévi-STRauss, C. (1991a): Las estructuras elementales del parentesco. Paidós. Barcelona.

LÉVI-STRAuss, C. (1991b): La familia en AA.VV. Polémica sobre el origen y la universalidad de la familia. Anagrama. Barcelona. 